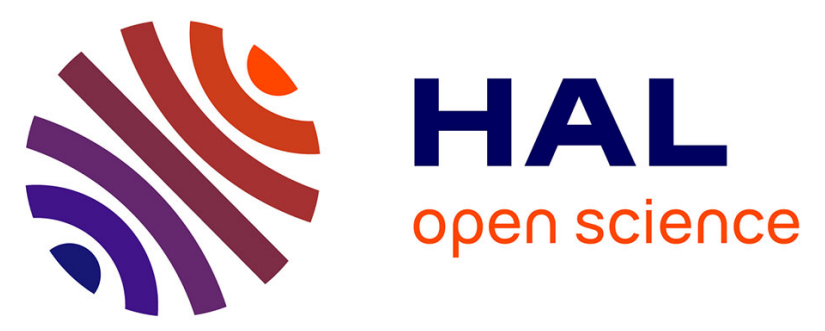

\title{
MOLECULAR EFFECTS IN THE SECONDARY ELECTRON EMISSION FROM ENTRANCE AND EXIT SURFACES OF THIN SOLID FOILS
}

K. Kroneberger, H. Rothard, M. Burkhard, J. Kemmler, P. Koschar, O. Heil, C. Biedermann, S. Lencinas, N. Keller, P. Lorenzen, et al.

\section{To cite this version:}

K. Kroneberger, H. Rothard, M. Burkhard, J. Kemmler, P. Koschar, et al.. MOLECULAR EFFECTS IN THE SECONDARY ELECTRON EMISSION FROM ENTRANCE AND EXIT SURFACES OF THIN SOLID FOILS. Journal de Physique Colloques, 1989, 50 (C2), pp.C2-99-C2-104. 10.1051/jphyscol:1989218 . jpa-00229415

\section{HAL Id: jpa-00229415 https://hal.science/jpa-00229415}

Submitted on 1 Jan 1989

HAL is a multi-disciplinary open access archive for the deposit and dissemination of scientific research documents, whether they are published or not. The documents may come from teaching and research institutions in France or abroad, or from public or private research centers.
L'archive ouverte pluridisciplinaire HAL, est destinée au dépôt et à la diffusion de documents scientifiques de niveau recherche, publiés ou non, émanant des établissements d'enseignement et de recherche français ou étrangers, des laboratoires publics ou privés. 


\title{
MOLECULAR EFFECTS IN THE SECONDARY ELECTRON EMISSION FROM ENTRANCE AND EXIT SURFACES OF THIN SOLID FOILS(1)
}

\author{
K. KRONEBERGER, H. ROTHARD, M. BURKHARD (2), J. KEMMLER, P. KOSCHAR, \\ O. HEIL, C. BIEDERMANN (3), S. LENCINAS, N. KELLER, P. LORENZEN, \\ D. HOFMANN, A. CLOUVAS ${ }^{(4)}$, E. VEJE ${ }^{(5)}$ and K.O. GROENEVELD \\ Institut für Kernphysik, J.W. Goethe-Universität, Frankfurt/Main, \\ F.R.G.
}

Resumé

Nous avons mesuré séparément le nombre des électrons émis par les surfaces avant et arrière des feuilles très minces ( 2 à $25 \mu g / \mathrm{cm}^{2}$ ) lorsqu'elles sont bombardées avec des projectiles atomiques et moléculaires rapides $(0.1$ à $1.2 \mathrm{MeV} / \mathrm{u})$. Les résultats obtenus sont comparés avec des simulations Monte Carlo du taux de perte d'énergie des projectiles moléculaires et avec le modèle de Brandt concernant le taux de perte d'énergie des agrégats dans le solide. Nous avons montré que la proportionalité entre le rendement d'émission secondaire électronique et le taux de perte d'énergie est valable aussi pour des projectiles moléculaires dans le domaine d'énergie étudié. Ces résultats nouveaux apportent des informations supplémentaires dans la compréhension de l'interaction ion-solide, par ex. l'étude des effets d'écran et du phénomène de sillage.

\section{Abstract}

We present results of the secondary electron emission coefficient $\gamma$ from thin foil targets (2 to $25 \mu \mathrm{g} / \mathrm{cm}^{2}$ ), for which we measured the secondary electron yields in backward $\left(\gamma_{b}\right)$ as well as in forward $\left(\gamma_{f}\right)$ direction separately, using both molecular ions and their atomic constituents as projectiles at 0.1 to $1.2 \mathrm{MeV} / \mathrm{u}$. The results are compared with monte carlo calculations of the electronic stopping power $S_{e}$ of molecular projectiles and with a modell for $S_{e}$ of clusters of Brandt et al. They show that the proportionality between Se and $\gamma$ also holds for molecular projectiles at different velocities ( $\left.v_{p} \approx v_{0}, v_{p} \Downarrow_{0}\right)$. Such measurements thus offer new possibilities for the understanding of ion-solid-interactions as e.g. the study of screening and wake phenomena.

\section{Introduction}

The secondary electron emission (SEE) from solids under ion bombardment has been found to be a powerful tool for the examination of ion-solid-interaction, especially with regard to the stopping power $/ 1,2,3,4 /$. The proportionality between the electronic stopping power $S_{e}$ and the secondary electron yield $\gamma$ is quite well established for a wide range of target materials $\left(Z_{T}\right)$, projectiles $\left(Z_{p}\right)$ and projectile velocities $\left(v_{p}\right) / 2,3,4 /$. In most experiments, though, monoatomic projectiles and thick targets were used, regarding only the backward electron emission. Therefore, using thin foils as targets and measuring both the backward $\left(\gamma_{b}\right)$ and forward $\left(\gamma_{f}\right)$ electron enission coefficients separately yields more information about the collision processes that take place inside the solid.

(1) Supported by BMFT, Bonn, No. 06 OF 173/2 Ti. 476

(2) Now at Kraftwerk-Union (KWU), Offenbach, F.R.G.

(3) Present address : University of Tennessee, Knoxville, TN 37996, U.S.A.. and Oak Ridge National Laboratory, Oak Ridge, TN 37831, U.S.A.

(4) Department of Electrical Engineering. Aristoteles Univ.. Thessalonik1. Greece

(5) H.C. Orstedt Institute, Kopenhagen, Denmark 
Sternglass divides the production of secondary electrons (SE) into two processes:

i) In close collisions fast electrons are produced, which Sternglass called $\delta$-electrons. Their angular distribution is peaked in forward direction, so they transport the fraction of the energy loss that goes into this process in forward direction, until they distribute their energy to slow SE in collision cascades within a distance L $\delta$ comparable with their range $/ 1,5,6 /$.

ii) Slow SE are directly produced by the projectile in distant collisions. Here the long range coulomb force of the projectile charge causes a distortion in the electron gas. This appears as a collective excitation of the electron plasma by which a small amount of energy $(\mathrm{E} \approx 25 \mathrm{eV})$ can be transferred to single electrons. These slow SE show a uniform angular distribution and most probably loose the ability to leave the solid if they suffer a collision with another electron.

The number of slow SE produced in each process is proportional to the fraction of the specific energy loss of the projectile, $\mathrm{dE} / \mathrm{dx}$, for each process, divided by their mean energy. They can be emitted from the solid if their origin lies within an escape depth Lse in the order of $10 \AA \leq L \mathrm{E} \leq 100 \AA / 1,6 /$. Thus, backward $\mathrm{SEE}$ should be dominated by $\mathrm{SE}$ from the second process, whereas forward SEE is determined by both processes.

The characteristic length that separates these two processes is the Debye screening length of the electron plasma, $\lambda_{d} \approx v_{p} / \omega_{p}$, with the projectile velocity $v_{p}$ and the plasma frequency $\omega_{p}$. At high velocities ( $\left.v_{p}\right) v_{0}$, with the Bohr velocity $\left.v_{0}\right)$ the total electronic energy loss is split up in equal parts to both processes (Bohr's "equipartition rule", /7/). At lower projectile velocities $\left(v_{p} \leq 2 v_{0}\right)$ the fraction of the energy loss entering the second process becomes smaller, due to the stronger screening of the projectile charge by the electron plasma. Below a critical velocity $v_{c}$, determined by $\omega_{0}$, the coupling between the projectile charge and the electron plasma is so weak that no more collective excitation should occur (Brandt's "partition rule" /8/).

With molecules or clusters as projectiles the distinction between close and distant collisions also plays an important role when studying the question, in which cases the atomic constituents of the molecule act like single, uncorrelated particles and in which cases they have to be regarded as a united charge when interacting with the target. The answer will depend strongly on the collision parameter $b$ and the internuclear separation $r_{x}$ between the atomic constituents, as can be seen from the processes discussed below.

The different interacting mechanisms of atomic and molecular projectiles can cause molecular effects which can be observed in the ratio between a physical quantity measured with molecular projectiles and the sum of the values measured with its atomic constituents. A ratio $R \neq 1$ signifies the appearance of a molecular effect. For SEE and energy loss measurements we define the ratios

$$
R(\gamma)=\frac{\gamma(\text { Molecule })}{\Sigma \gamma(\text { atomic const. })} \quad ; R(\mathrm{dE} / \mathrm{dx})=\frac{\mathrm{dE} / \mathrm{dx} \text { (Molecule) }}{\Sigma \mathrm{dE} / \mathrm{dx}(\text { atomic const. })} \quad \text { eq. (1). }
$$

Here molecular effects can originate from the following processes:

a) The binding electron(s) can screen the projectile charge and thus decrease the SE yield of the molecule, causing $R<1$.

b) When the binding electron(s) are lost in the entrance surface layers, they can also contribute to the SE yield in addition to the atomic constituents of the molecule, so that $\mathrm{R}>1$.

c) As long as $r_{x}<\lambda_{d}$, the charges of the atomic constituents act as a united charge with regard to distant collisions. Depending on the strength of the screening of the projectile charge by the electron plasma this united charge can be larger or smaller than the sum of the charges of the atomic constituents.

d) The wake potential of a leading particle may effect the energy loss of the trailing particle, respectively the superimposed wake potentials of the atomic constituents may influence the energy loss of the molecular projectile as a whole $/ 9,10 /$.

The internuclear separation between the atomic constituents on their way through the solid increases due to the coulomb explosion and multiple scattering. Thus the molecular effects will decrease in forward direction with increasing target thickness, as will the contribution of the binding electron(s) to a molecular effect. This can only be studied by measuring the SE yields from both the entrance and the exit surfaces of thin target foils.

\section{Experiment}

Most of the experimental set-up is described in detail in $/ 6 /$. In the present set-up, however, experiments were carried out in an ultra high vacuum (UHV) chamber and with sputter cleaned target foils /11/. Clean surfaces are essential for the measurement of $\gamma$, since the SE yield strongly depends on the surface conditions, and for the definition of up and thus $\lambda_{d}$ in the last layers of the foil, where most emitted SE originate. 
Experiments were carried out with $\mathrm{H}^{*}, \mathrm{H}^{\circ}, \mathrm{H}_{2}{ }^{+}(1.2 \mathrm{MeV} / \mathrm{u})$ and $\mathrm{C}^{*}, \mathrm{O}^{+}, \mathrm{CO}^{+}\left(15 \mathrm{keV} / \mathrm{u}<\mathrm{Ep}_{\mathrm{p}}\right.$ $<85 \mathrm{keV} / \mathrm{u})$ as projectiles, and $\mathrm{C}-$, Al- and Cu-foils $(100 \AA<\mathrm{x}<1000 \AA)$ as targets. The results with hydrogen projectiles are found in $/ 6 /$.

\section{Results}

In our first experiment we measured the SE yield at $v_{p} \approx 7 \mathrm{vo}$ in dependence of the target foil thickness. Fig. 1 presents the "molecular effect ratio" for the backward, $R\left(\gamma_{\mathrm{b}}\right)$, and forward, $\mathrm{R}\left(\gamma_{\mathrm{f}}\right)$, SE yields from $\mathrm{H}^{+}, \mathrm{H}^{\circ}, \mathrm{Hz}_{2}+(1.2 \mathrm{MeV} / \mathrm{u})$ projectiles penetrating carbon foils of the specific thickness $2 \mu \mathrm{g} / \mathrm{cm}^{2}<\varrho x<25 \mu \mathrm{g} / \mathrm{cm}^{2}$ (from /6/). The empty squares represent the ratio regarding the additional yield of the binding electron, for the ratio represented by the full squares only the sum of the yields of two independent protons was taken into account.

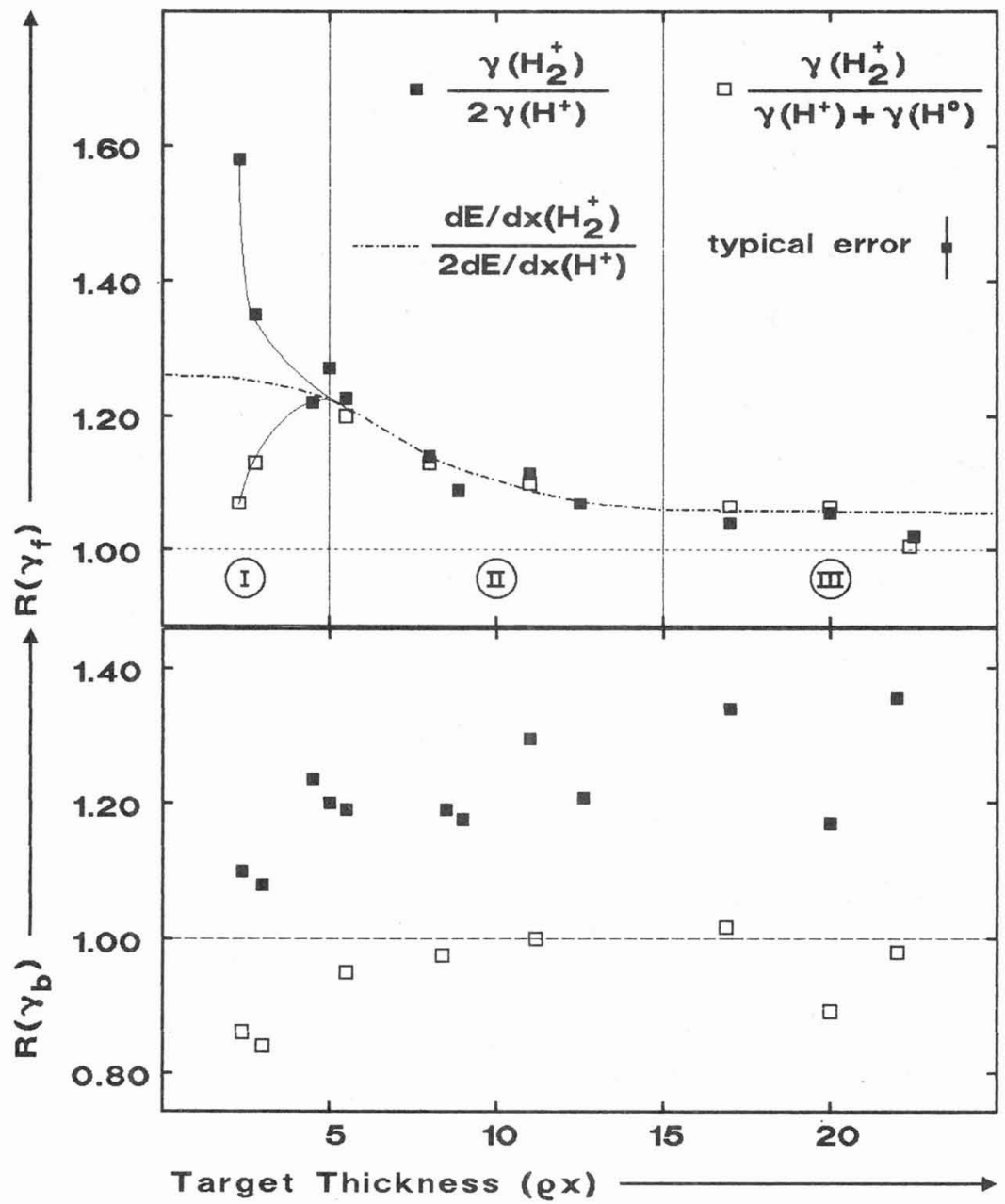

Fig. 1: Molecular effect ratio $R\left(\gamma_{f}\right)$ (top) and $R\left(\gamma_{b}\right)$ (bottom) for $H^{+}, H^{\circ}$ and $H_{2}{ }^{+}$ (1.2MeV/u) traversing $\mathrm{C}$-foils $\left(2\right.$ to $\left.25 \mathrm{\mu g} / \mathrm{cm}^{2}\right)$. Empty squares: ratios regarding the yield of the binding electron; full squares: ratio regarding only two protons. Dotted line (.-.-.): energy loss of $\mathrm{Hz}^{+}$(Monte Carlo calculation) divided by twice the energy loss of a proton (see text). From $/ 6 /$.

In backward direction the molecular effect is caused mainly by the binding electron, which contributes to $\gamma_{b}$ with about 0.6 electrons $/ 6,12 /$. The ratio regarding the binding electron is slightly below unity, indicating that additionally the charge of the molecule is screened by the electron. 
In forward direction, however, only for small target thicknesses $\left(\mathrm{x}<250 \AA, \mathrm{ex}<5 \mu \mathrm{g} / \mathrm{cm}^{2}\right)$, region $I$, the binding electron contributes to a molecular effect. In region II $\left(5 \mu \mathrm{g} / \mathrm{cm}^{2}<\mathrm{Qx}<15 \mu \mathrm{g} / \mathrm{cm}^{2}\right)$ the molecular effect in an order of up to $R\left(\gamma_{\mathrm{f}}\right) \approx 1.2$ is caused by the correlated motion of the two protons through the solid, while in region III ( $\mathrm{\rho x}>15 \mu \mathrm{g} / \mathrm{cm}^{2}$ ) the two protons have separated so far that $R \approx 1$. We calculated the energy loss of this proton dicluster in the last $50 \AA$ of the foil, where most emitted SE originate, using a monte carlo procedure described in $/ 9 \%$. The ratio between this calculated energy loss and the energy loss of two independent protons is in very good agreement with the measured SE yield ratio in region II and III. For target thicknesses $\varrho x<2 \mu g / \mathrm{cm}^{2}$ it reaches a constant value of $R(d E / d x) \approx 1.26$. Energy loss calculations by Brandt et al. /13/ show about the same energy loss ratio, $R(d E / d x)=1.28$, for proton diclusters that have not yet separated due to coulomb explosion or multiscattering, which is the case for very thin ( $\left.\mathrm{ex} \ll 1 \mu \mathrm{g} / \mathrm{cm}^{2}\right) \mathrm{targets}$. These results support, at high velocities, the proportionality between energy loss and SE yield also for molecular projectiles, as well as the validity of Brandt's energy loss model for clusters.

In our second experiment we measured $\gamma_{f}$ and $\gamma_{b}$ from thin foils with molecular projectiles in dependence of the projectile velocity in the region $v_{0}\left\langle v_{p}<2 v_{0}\right.$ with $\mathrm{CO}^{+}-$projectiles. In order to study the influence of the screening by the electron gas of the solid we used targets with different plasma frequencies $\omega_{p}$ and thus with different screening lengths, namely $\mathrm{C}\left(\hbar \omega_{\mathrm{p}} \approx 21 \mathrm{eV}\right)$ and $\mathrm{Al}\left(\hbar \omega_{\mathrm{p}} \approx 15 \mathrm{eV}\right)$, under ultra high vacuum conditions $\left(\mathrm{P} \approx 2 * 10^{-9} \mathrm{hPa}\right)$ and with sputter cleaned surfaces.

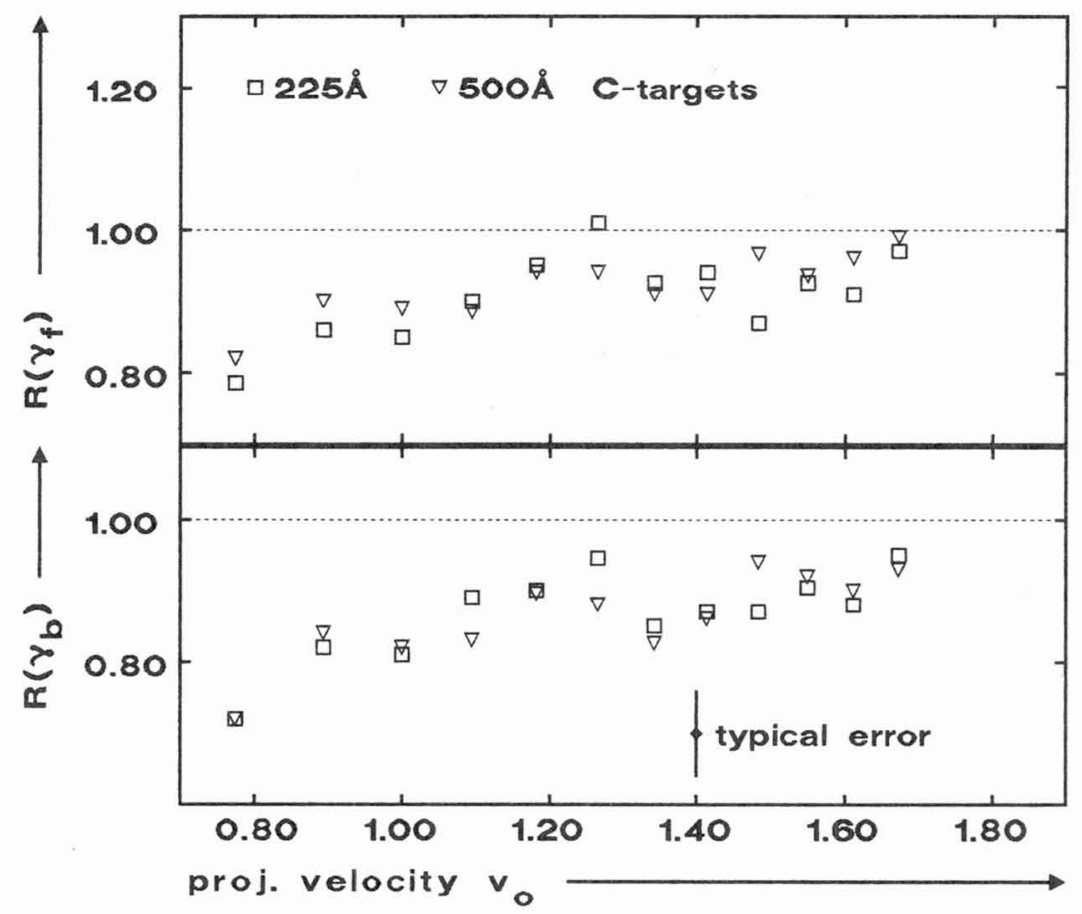

Fig. 2; Forward $\left(R\left(\gamma_{f}\right)\right.$, top) and backward $\left(R\left(\gamma_{b}\right)\right.$, bottom) SE yield ratio for $C O^{+}$ respectively $\mathrm{C}^{+}$and $\mathrm{O}^{+}$projectiles of 15 to $75 \mathrm{keV} / \mathrm{u}$ penetrating Carbon foils.

Fig. 2 presents the "molecular effect ratio" in dependence of the projectile velocity in forward, $R\left(\gamma_{f}\right)$, and backward, $R\left(\gamma_{b}\right)$, direction from C-foils. Fig. 3 presents the corresponding data for Al-foils. At $v_{p}<v_{0}$ the backward SE yield ratio is in the order of $R\left(\gamma_{b}\right) \approx 0.7$ for both targets and for all target thicknesses. With increasing velocity it increases towards a value of $R\left(\gamma_{b}\right) \approx 0.9$ which is reached at $v_{p} \approx 1.3 v_{0}$ for $C$-foils respectively at $v_{p} \approx 1.1 v_{0}$ for Al-foils. These velocities reflect the strength of the screening and thus the plasma frequency in each target material, 'which is higher in C-foils than in Al-foils.

For low velocities ( $\mathrm{v}_{\mathbf{p}}<2 \mathrm{v}_{\mathrm{o}}$ ) Brandt's calculations show a decrease of the energy loss ratio towards $R(d E / d x) \approx 1$ at $v_{p} \approx 1.5 v_{0}$. Recent results for $y_{b}$ from thick targets with $H_{2}{ }^{+}$ projectiles follow this tendency even continuing to $R\left(\gamma_{b}\right)<1$ at $v_{p}<1.5 v_{0} / 2 /$. This decrease was interpreted merely as a screening of the molecular projectile charge by the binding 
electron. Our results, though, show that also the screening by the electron plasma of the solid plays an important role.

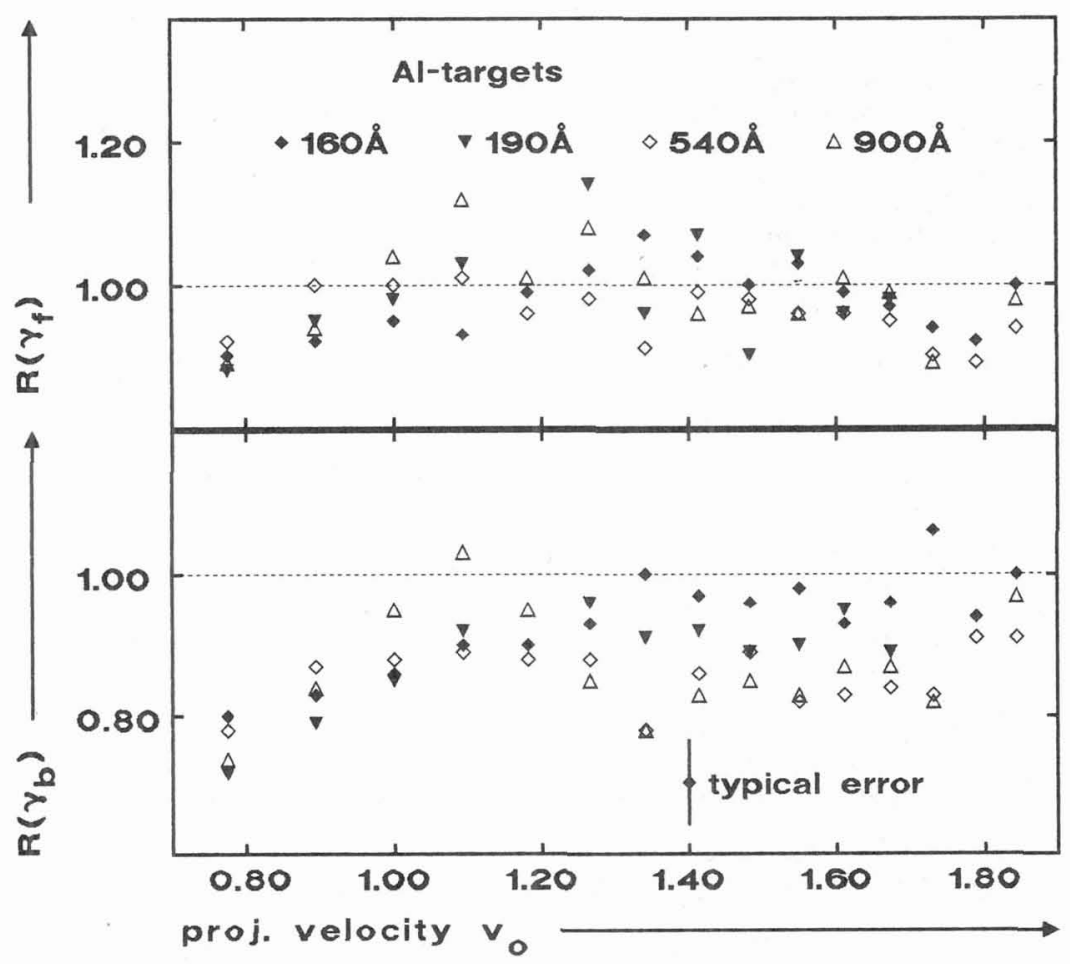

Fig. 3: Forward ( $R\left(\gamma_{f}\right)$, top) and backward ( $\left(\gamma_{b}\right)$, bottom) SE yield ratio for $C O^{*}$ respectively $C^{+}$and $O^{+}$projectiles of 15 to $85 \mathrm{keV} / \mathrm{u}$ penetrating Aluminium foils.

Since the binding electron of the molecular projectile is lost in the first few layers of the target foil $/ 14,15 /$, it should not effect the forward SEE after a target thickness larger than its range (see $\mathrm{H}_{2}{ }^{*}$-data and /6/). Indeed in forward direction the molecular effect is not as pronounced as in backward direction. It starts off with a value of $R\left(\gamma_{f}\right) \approx 0.8 \ldots 0.9$ at $v_{p}<v_{0}$ and reaches $R\left(\gamma_{f}\right) \approx 1$ at $1.3 v_{0}$ (C) respectively $1.1 v_{0}$ (Al-foils). Yet, it is surprising that any molecular effect can be observed at all, since for the target thicknesses and velocities used here (after about $100 \AA$ at $v_{p} \approx v_{0}$ and $250 \AA$ at $\left.v_{p} \approx 1.5 v_{0}\right) r_{x}$, merely because of multiscattering, should already be much larger than $\lambda_{d}$. In this case the atomic constituents would act as independent projectiles, not giving rise to molecular ef fects.

Though, other experiments carried out with $\mathrm{N}_{2}+$-projectiles $/ 10 /$ also show $\mathrm{R}(\mathrm{dE} / \mathrm{dx}) \approx 0.9$ at target thicknesses comparable to ours. Also, monte-carlo-calculations for $r_{x}$ of $\mathrm{CO}^{+}$at low velocities $\left(v_{p} \approx v_{0}\right) / 9 /$ and experiments with different molecules /16/ indicate that the atomic constituents may stay together for rather large distances (some 100A), if one particle is captured in the first minimum of the wake potential of the leading particle.

In similar experiments, where only the total SE yield was measured $/ 3 /$, an oscillatory behaviour of $R(\gamma)$ was found when plotted versus the ratio between $r_{x}$ and the wake wavelength $\lambda_{w}=2 \pi \lambda_{d}$. This was interpreted as an interference effect of the wake potentials of the atomic constituents on the exit of the solid. In $/ 3 / r_{x}$ had been calculated only regarding the coulomb explosion, and a phase shift, explained by multiple scattering, had to be put in the data for different target thicknesses to obtain the oscillation. We calculated $r_{x}$ with the monte carlo procedure from /9/ which includes multiple scattering and wake forces. Within the error bars of $15 \%$ we found no oscillations in $R\left(\gamma_{f}\right)$ that confirm the interpretation of $/ 3 /$.

We measured the Secondary Electron yield coefficients in forward $\left(\gamma_{f}\right)$ and backward ( $\left.\gamma_{b}\right)$ direction from thin solid foils (C and $\mathrm{Al}$ ) with molecular projectiles. Both for high $\left(v_{p} \approx 7 v_{0}\right)$ and low $\left(v_{p} \approx v_{0}\right)$ projectile velocities we found a proportionality between the 
measured SE yield and the energy loss of the cluster projectiles, a) calculated with a monte carlo procedure $/ 9 /$ and $b)$ with the calculations of Brandt /13/. By measuring the SE yields from both entrance and exit surface of the foils we found molecular effects not only caused by the binding electron of the molecule but also such due to the united charge of the atomic constituents of the cluster.

The united charge of the cluster depends on both the screening by the binding electron and the screening by the electron gas of the solid, which is stronger at lower than at higher projectile velocities. A depency on the plasma frequency of the electron gas, w, could be measured with two target materials with different w, namely $\mathrm{C}$ and $\mathrm{Al}$. These measurements were carried out in an ultra high vacuum chamber and the target foils were sputtered to achieve clean surfaces.

The proportionality between energy loss and SE yield, stated in the modell of Sternglass, was found to hold also in the Bohr velocity region and for molecular projectiles, for which the energy loss ratio calculations by Brandt are in good agreement with our SE yield ratios.

SEE may thus become a powerful tool to measure the energy loss of molecules or to test energy loss models.

\section{References}

/1/ E. J. Sternglass, Phys. Rev. 108 (1957) 1

/2/ D. Hasselkamp, J. Liebig Univ. Giessen, Germany, Habilitationsschrift (1985)

/3/ H. J. Frischkorn, K. O. E. Groeneveld, Phys. Scripta T6 (1983) 89

14/ A. Clouvas, R. G. Kirsch, A. Katsanos, P. Misaelides, M. Burkhard, H. Rothard, C. Biedermann, J. Kemmler, K. Kroneberger, K. O. Groeneveld, to be published

/5/ P. Koschar, K. Kroneberger, A. Clouvas, R. Schramm, H. -D. Betz, M. Burkhard, O. Heil, J. Kenmler, H. Rothard, K. O. Groeneveld, this conference

/6/ K. Kroneberger, A. Clouvas, G. Schlüssler, P. Koschar, J. Kemmler, H. Rothard, C. Biedermann, O. Heil, M. Burkhard, K. O. Groeneveld, Nucl. Instr. Meth. B29 (1988) 621

/7/ N. Bohr, K. Dan. Vid. Selsk. Mat. Fys. Medd. 18 No.8 (1948)

/8/ W. Brandt, J. Reinheimer, Phys. Rev. B2 (1970) 3104

19/ J. Kemmler, P. Koschar, M. Burkhard, K. O. Groeneveld, Nucl. Instr. Meth. B12 (1985) 62

/10/ M. F. Steuer, D. S. Gemmel1, E. P. Kanter, E. A. Johnson, B. J. Zabransky, IEEE Trans. Nucl. Sci., Vol. NS30 (1983) 1069

111/ M. Burkhard, H. Rothard, J. Kemmler, K. Kroneberger, K. O. Groeneveld, J. Phys. D21 (1988) 472

and M. Burkhard, W. Lotz, K. O. Groeneveld, J. Phys. E21 (1988) 759

/12/ J. Hölzl, K. Jacobi, Surf. Sci. 14 (1969) 351

/13/ W. Brandt, R. H. Ritchie, Nucl. Instr. Meth. 132 (1976) 43

/14/ N. Cue, N. V. de Castro Faria, M. J. Gaillard, J. C. Poizat, J. Remillieux, Nucl. Instr. Meth 170 (1980) 67

115/ A. Clouvas, M. J. Gaillard, A. G. de Pinho, J. C. Poizat, J. Remillieux, J. Desesquelles, Nucl. Instr. Meth. B2 (1984) 273

/16/ E. P. Kanter, P. J. Cooney, Phys. Rev. A20 (1979) 834 